\title{
Comparative Study of the Stridulatory Sulcus, Buccula and Rostrum of the Nymphs of Triatoma guazu Lent \& Wygodzinsky, 1979 and Triatoma jurbergi Carcavallo, Galvão \& Lent, 1998 by Scanning Electron Microscopy (Hemiptera, Reduviidae)
}

\author{
Maria Beatriz Araújo Silva, Helene Santos Barbosa* , Cleber Galvão/ ${ }^{+}$, José Jurberg, \\ Rodolfo U Carcavallo
}

\begin{abstract}
Laboratório Nacional e Internacional de Referência em Taxonomia de Triatomíneos, Departamento de Entomologia
*Laboratório de Ultra-estrutura Celular, Departamento de Ultra-estrutura e Biologia Celular, Instituto Oswaldo Cruz-Fiocruz, Av. Brasil 4365, 21045-900 Rio de Janeiro, Brasil
\end{abstract}

The ultrastructural morphology of the ventral region of the head (rostrum and buccula) and proesternum (stridulatory sulcus) of nymphs from the 1st to 5th instars of Triatoma guazu Lent \& Wygodzinsky, 1979 and Triatoma jurbergi Carcavallo, Galvão \& Lent, 1998 was described. Morphological differences between the two species and of the five nymphal stages development of each species were observed. These structures showed systematic differential characteristics of the studied species and may be used to increase their taxonomic range.

Key words: Triatominae - Chagas disease vectors - buccula - stridulatory sulcus - rostrum

Chagas disease constitutes a major public health in Latin America. It is caused by infection with the protozoan parasite Trypanosoma cruzi (Chagas, 1909), mainly transmitted in the faecal droppings of triatomine bugs. Actually the subfamily Triatominae is composed of 138 species, all characterized by their obligate haematophagy (Carcavallo et al. 2002, Galvão et al. 2002). These insects are distributed in the Americas and some species are found in the Old World. Its geographic distribution is wide, being found in the Neartic Region between the latitudes $42^{\circ} \mathrm{N}$, in Salt Lake City in the North of America (USA) until the Neotropical region $46^{\circ} \mathrm{S}$ in the Patagonia, with occurrences of some species in the Oriental region (Jurberg 1996).

Triatoma guazu Lent \& Wygodzinsky, 1979 and Triatoma jurbergi Carcavallo, Galvão \& Lent, 1998 are related species present in the state of Mato Grosso, Brazil, between the latitudes of $15^{\circ} 49^{\prime} 01^{\prime \prime}$ and $16^{\circ} 43^{\prime} 10^{\prime \prime} \mathrm{S}$. These species belong to the oliverai complex, considered to be a very homogeneous group according to morphological characteristics (Carcavallo et al. 2000).

The Triatominae taxonomy is based on the external morphological characters (Lent \& Wygodzinsky 1979). During the last decade, the scanning electron microscopy (SEM) has been used as an important tool for Triatominae systematics, clearing the status of the cryptic species and their complexes.

Supported by CNPq, Funasa/Fiocruz and Faperj.

${ }^{+}$Corresponding author. Fax: $+55-21-2573.4468$. E-mail: galvao@ioc.fiocruz.br

Received 17 September 2002

Accepted 12 March 2003
Studies by Pinto (1931) reveal the importance of the rostrum in the characterization of the genera of Triatominae, considering that the length of the articles of the rostrum in the Hemiptera in general, especially in the haematophagous families is important for the systematic of these insects.

Carcavallo et al. (1994) studied 11 species of Panstrongylus genus using SEM, considering P. herreri, $P$. humeralis and P. lignarius as related species. Later, Carcavallo et al. (1995), comparing various anatomic zones of genus Psammolestes Bergroth, 1911, found important differences between the species. This methodology was the principal tool used to study 97 of 110 species of Triatominae (Carcavallo et al. 1998), which has been employed by Ferro et al. (1997) to analyze structures of buccula and gula of nymphs of 5th instar of Triatoma williami Galvão, Souza \& Lima, 1965 and Triatoma gerstaeckeri (Stål, 1859).

Our group has developed a series of papers in the study of the comparative morphologic characterization between $T$. guazu and T. jurbergi demonstrating little known structures of 1 st instar nymphs of $T$. guazu such as proesternum, antenniferous tubercle and the articulations between the antennal segments (Silva et al. 1998), partial results of apical plate morphology of first instar of both species (Silva et al. 1999), description of the five instars nymphs and in the exochorion of eggs through optical and scanning electron microscopy (Silva et al. 2000, Jurberg et al. 2002) and more recently, a comparative ultrastructural analysis of the antenna of $T$. guazu and $T$. jurbergi during the nymphal stage describing characteristics that allowed the taxonomic separation of the nymphs of these two species (Silva et al. 2002).

In the present study, morphological structures of head and proesternum as the stridulatory sulcus, buccula and rostrum, of nymphs from the 1 st to 5 th instar of $T$. guazu and $T$. jurbergi, were compared using scanning electron microscopy. 


\section{MATERIALS AND METHODS}

Insects - The five nymph stages of T. guazu and T. jurbergi were obtained from acclimatized colonies that were respectively started in 1996 and 1997, at the insectary of the Laboratório Nacional e Internacional de Referência em Taxonomia de Triatomíneos of the Departamento de Entomologia of the Instituto Oswaldo Cruz, Rio de Janeiro, Brazil. These colonies were established with insects from Rondonópolis and Barra do Garças, Mato Grosso, sent by the Fundação Nacional de Saúde. All material analyzed belongs to the Rodolfo Carcavallo Collection at the Departamento de Entomologia, Instituto Oswaldo Cruz.

SEM - Ventral views of the head and prosternum of three nymphs of each instar (1st to 5th instar) of the two species were analyzed. The 1 st instar nymphs were collected soon after hatching, killed by freezing and adhered to metal stubs with $1.2 \mathrm{~cm}$ of diameter using double-faced sticky tape. Due to the small diameter of the stubs, the cephalic region of the nymphs of 4 th and 5 th instars were cut with a scalpel and adhered to the stubs exposing either the dorsal or the ventral surface. The mounted specimens were sputter-coated with gold and observed under a Zeiss DSM 940 scanning electron microscope, operated at $15 \mathrm{kV}$. The images were either photographed with Neopan SS 120 Fuji film or digitally captured by IBM-PC computer and processed using the Adobe Photo Shop 5.0 software.

\section{RESULTS}

In order to get more informations about the morphology of the of 1 st to 5 th instars of T. guazu and T. jurbergi, the ventral views of the head (rostrum and buculla) and the proesternum (stridulatory sulcus) of Triatominae bugs were examined in the present paper.

Triatoma guazu - The structure of the prosternum region of nymphs from the 1 st instar of $T$. guazu shows a central area with rudimentary horizontal striae, the future stridulatory sulcus. A granular area surrounding the central region was observed, where papillae and sensilla shall be present in the 2nd to 5 th instar (Fig. 2 A). The anterior edge presents in prominence two wide sensilla, observed in all the instars (Figs $2 \mathrm{~A}-\mathrm{E}$ ). From the 2nd to 4th instar, the sulcus is fine and long with well defined parallel striae. Along the development, the anterior edge of the sulcus becomes straighter, the posterior edge was gauged and the striae condensed (Figs 2 B-E). The 5th instar nymphs show a wider "V" shaped stridulatory sulcus (Fig. 2 E). Papillae and sensilla are present in setiferous tubercles, limiting the depression of stridulatory sulcus insertion, increasing in number during the nymphal development (Figs $2 \mathrm{~A}-\mathrm{E}$ ).

The buccula, localized in the protero-ventral region of the rostrum, is "U" shaped with thick edges. During the nymphal development, the edges of the buccula seem like a depression with two lateral groves, central rifts and a granular texture in the antero-central region (Figs $3 \mathrm{~A}-\mathrm{D}$ ). Nymphs of 5th instar loose the depression in this region, which differentiates it of the other instars (Fig. 3 E). A finger-like structure with flat boards is observed in the posterior region of each edge (Figs $3 \mathrm{~A}-\mathrm{E}$ ). This structure is rounded in the 1 st instar. Starting from the 2 nd instar, it is more elongated, with flat and well delimited boards. Internally, an area with a flat and glabrous surface with granulations in its superior region can be seen, which presents longitudinal striations on the first segment of the rostrum, more evident during the nymphal development. The central region of the buccula of the 1 st instar has a split depression in the anterior area $1+1$ and two longitudinal lateral depressions, forming a gutter, which is internally limited by granular pleats (Fig. 3 A). This intern structure modifies in the 2nd and 3rd instars and in the 4th instar forms an unique structure with a long central sulcus, which is short, apical and with granular texture in the 5th instar (Figs 3 B-E).
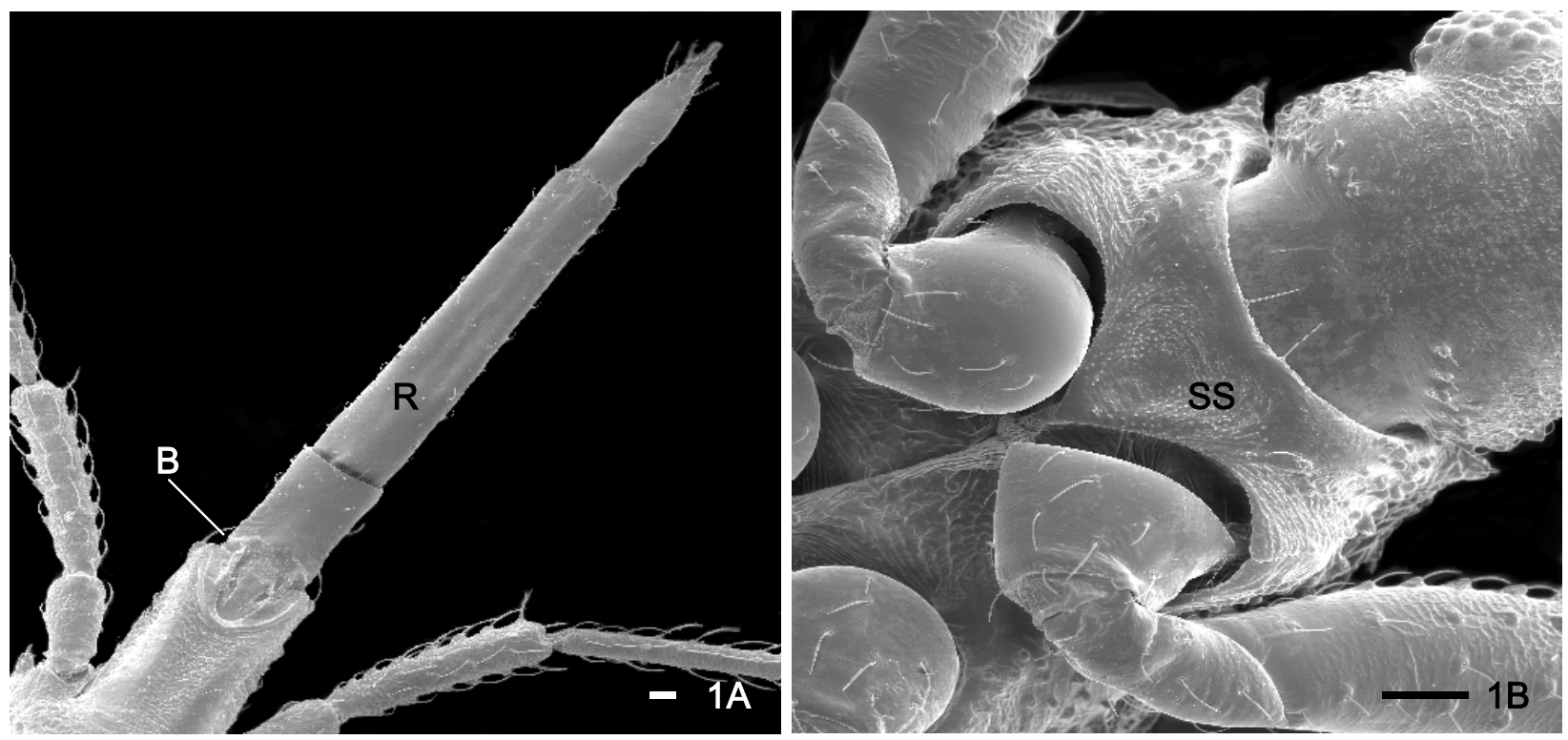

Fig. 1A: ventral views of the areas of the head rostrum (R) and buccula (B). Fig. 1B: proesternum stridulatory sulcus (SS) of Triatominae bugs studied in the present paper. All bars $=50 \mu \mathrm{m}$ 


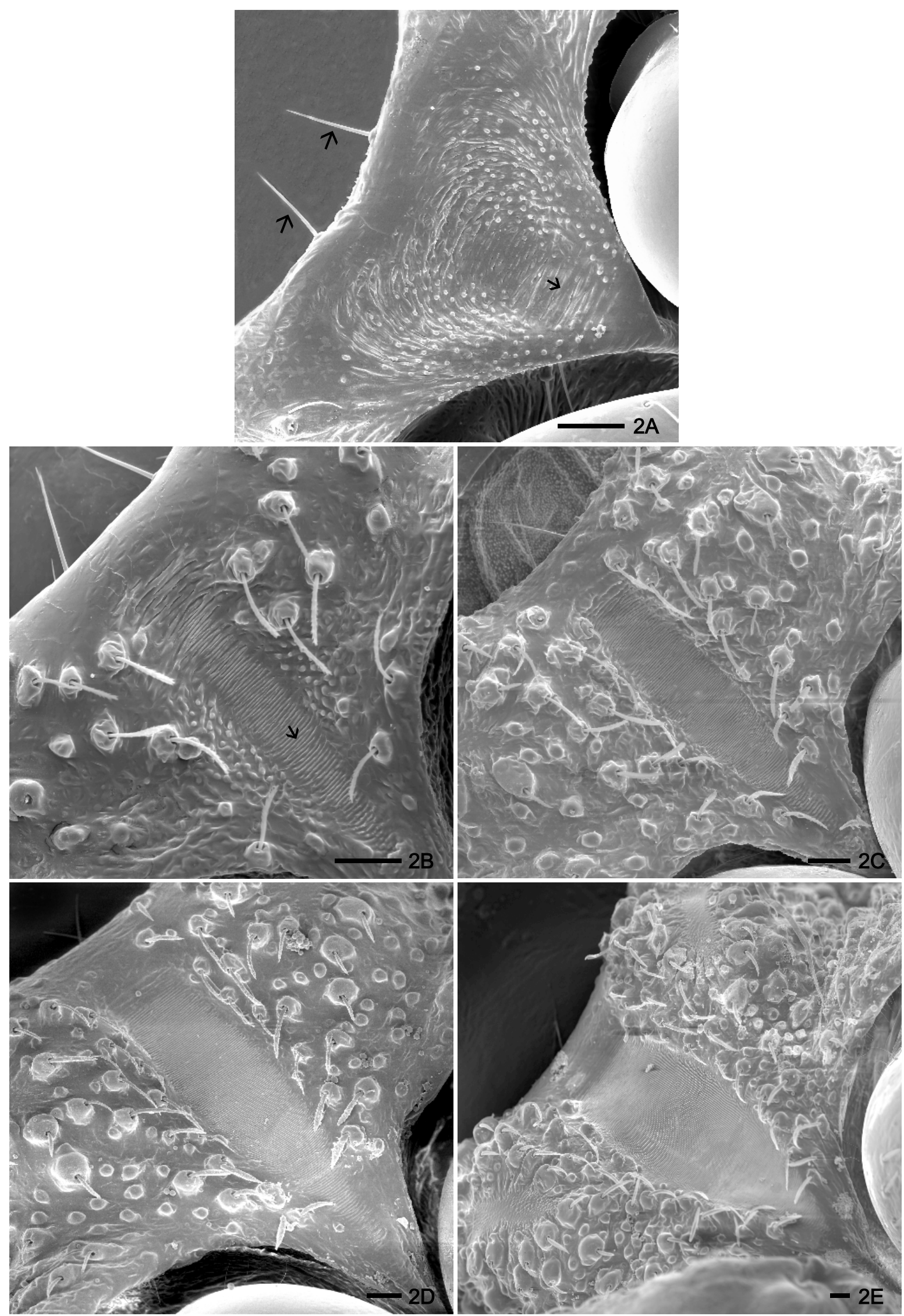

Fig. 2: Triatoma guazu Lent \& Wygodzinsky, 1979, ventral view: prosternum and stridulatory sulcus. A: 1st instar (the small arrow shows rudimentary horizontal striae; the arrows show two sensillae); B: 2nd instar; C: 3rd instar; D: 4th instar; E: 5th instar 


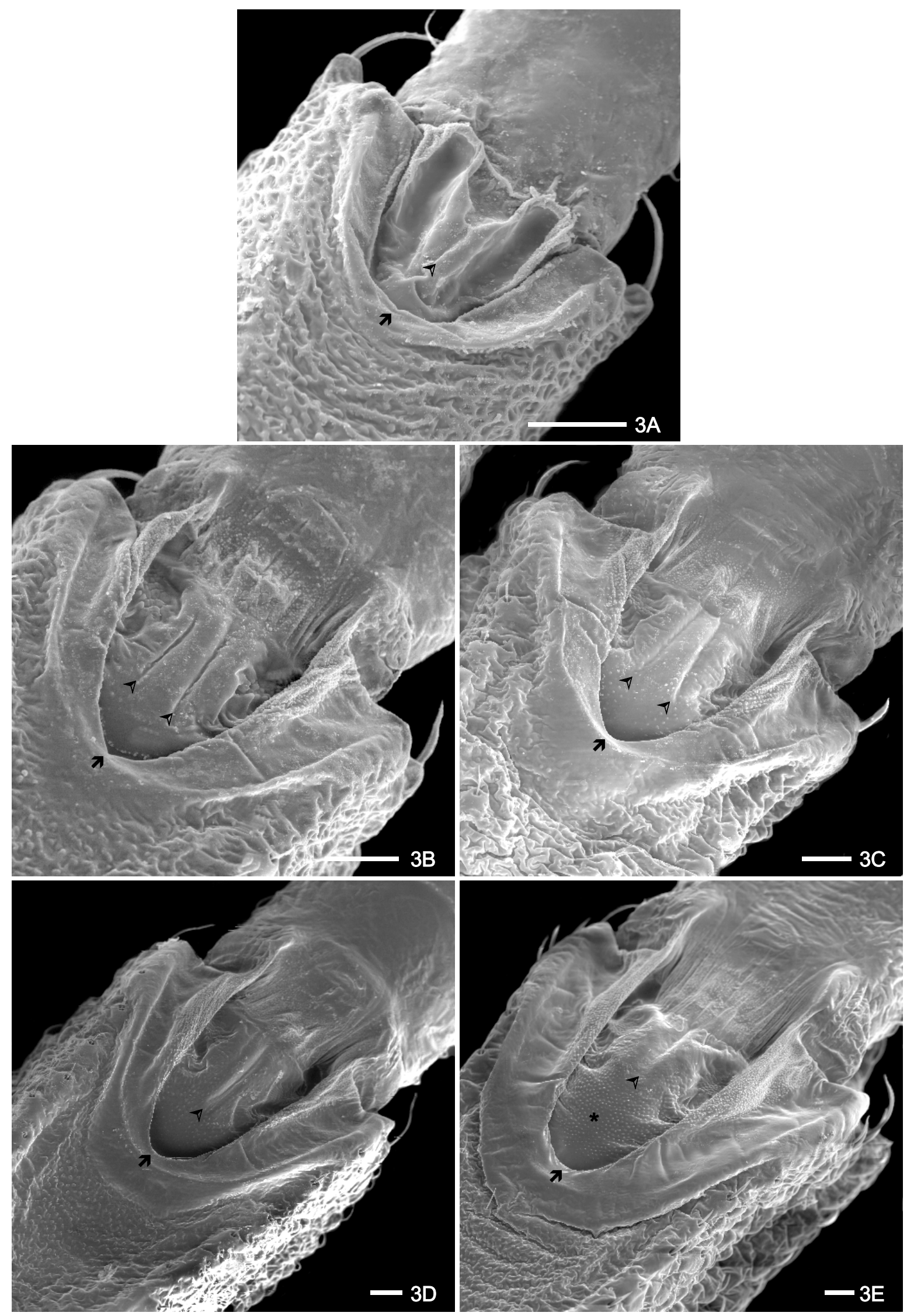

Fig. 3: Triatoma guazu Lent \& Wygodzinsky, 1979, ventral view: buccula (the arrows show sulcus and the arrow heads split depressions). A: 1st instar; B: 2nd instar; C: 3rd instar; D: 4th instar; E: 5th instar 
The rostrum is inserted in an arched area of the apex of the labium. It presents at the terminal region a pair of structures localized on the ventral and medial region (Fig. 4A). The basal part is welded with the labium and the free apex is constituted of $1+1$ lamellae to foliate one upon the other, which receive the name of "apical plate" (Figs 4 AE). The proximal lamella is wide and the distal lamella is narrower, limited laterally by two short and gauged sensillae 1+1 (Figs 4 A-E). Below the apical plate is a pair of long sensillae (Figs 4 A-E) and short sensillae are in parallel aligned position, already visible in the 1 st and 2 nd instars (Figs 4 A-B). During the nymphal development a considerable increase in the number, type and sensilla length is observed below the apical plate and in the lateral area of the rostrum (Figs 4 C-E). The presence of two lateral rifts $(1+1)$ is observed close to the apex of the rostrum (Figs 4 A-E).

Triatoma jurbergi - The stridulatory sulcus is "V" shaped and large up to the 1st to 5th instar, with a deep central concavity (Figs 5 A-E). Laterally, it is delimited by papillae and sensillae, inserted in setiferous tubercula and it presents central parallel grooves that are compressed during the development of the instars. The posterior edge of this structure narrowed gradually during the nymphal development.

The buccula of T. jurbergi is " $\mathrm{U}$ " shaped with thick edges and presents pleats and a granular surface. The anterior region shows accentuated straight pleats, present in all instars (Figs 6 A-E). The central region presents three rudimentary rifts in the 1st instar (Fig. 6 A). Small granulations appear up and one longitudinal rift is observed from the 2nd to the 4th instar (Figs 6 B-D) that disappeared in the 5th instar (Fig. 6 E).

The rostrum in T. jurbergi is similar to T. guazu (Figs 7 A-E). The apical plate has a lozenge formed inferior lamella and the superior one has a digit form. This structure is laterally delimited by $3+3$ sensillae, which gradually increase in length, during the nymphal development. Two very long and fine sensillae were inserted in tubercles of a short and circular basis in the 1st instar (Fig. 7 A). The number and length of sensillae in the third segment of the rostrum increase during the nymphal development presenting a parallel distribution. Two lateral rifts $1+1$ were observed at the apex of the rostrum.

\section{DISCUSSION}

Considering that $T$. jurbergi has been found naturally infected with Trypanosoma cruzi, a comparative mor- phological study is related between $T$. guazu and $T$. jurbergi. We have analyzed the buccula, rostrum and the stridulatory sulcus from the 1st to the 5th instars of $T$. guazu and T. jurbergi. They demonstrated particular characteristics during the nymphal development that can be used as taxonomical data (Table).

The studies developed by Lent and Wygodzinsky (1979) point out the taxonomic importance of the stridulatory sulcus for characterization of the species, which varies in form, length, number and spacing of grooves. These characteristics can aid in the determination of the species. In the present study it was possible to verify that nymphs of T. guazu and T. jurbergi present different morphology of the stridulatory sulcus in all the instars. In contrast, Costa et al. (1991) studying the nymphs and adults of Cavernicola lenti Barrett \& Arias, 1985, observed that this structure is absent in nymphs and vestigial in adults. In the species studied here, the stridulatory sulcus narrowed and prolonged in $T$. guazu in the 2 nd and 3rd instars, while, in T. jurbergi, this structure is enlarged and the posterior region is very gauged.

Ferro et al. (1997) studied the buccula and the gula of nymphs of the 1st and 5th instars of Triatoma williami Galvão, Souza \& Lima, 1965 and Triatoma gerstaeckeri (Stål, 1859), and described differences in the structures of the two species. The buccula was studied by Barth (1953) and Galíndez-Girón et al. (1998), who suggested that the function of the buccula in addition to the genas is to support the labium. The buccula of T. guazu and T. jurbergi studied here in all instars showed differences of boards in the central region, which presents two structures in gutter form only in the 1st instar of T. guazu, and two rifts $1+1$ in the 2nd and 3rd instars, which melt in only one rift in the 4th and 5th instars. This structure in T. jurbergi showed peculiar characteristics: in the 1st instar, the central region shows three rudimental rifts and only one in the 2 nd until the 4th instars, being almost absent in the 5 th instar.

Catalá (1996) studying ten species of the rostrum sensillae of eight species of Triatominae, observed that the sensilla type chaetica is more abundant along the surface of the rostrum, distributed in six columns along most of the $2 \mathrm{nd}$ and $3 \mathrm{rd}$ segments, increasing in number on the last segment. In the present study, columns of sensillae along the principal axis on the ventral surface of the 3rd segment of the rostrum in both species were observed. The sensillae increased in size and number during the development of nymphs. The main difference between

TABLE

Main differences observed between the nymphal instars of Triatoma guazu and Triatoma jurbergi, by scanning electron microscopy

\begin{tabular}{ll}
\hline T. guazu & Turbergi
\end{tabular}

Stridulatory sulcus in 2nd and 3rd instars, fine and long

Buccula structure in gutter form in the 1 st instar $(1+1)$. The central area in the 2 nd and 3 rd instars shows two rifts $(1+1)$ that are united in a unique rift in the 4th and 5th instars

Apical plate of rostrum delimited by $1+1$ sensillae of a more or less constant length
Stridulatory sulcus in 2nd e 3rd instars wide and with a pronounced narrowing in the subsequent area

Buccula: presence of three rudimentary rifts in the 1st instar and just one from the 2 nd to the 4 th instars, being practically absent in the 5 th instar

Apical plate of rostrum delimited by $3+3$ sensillae that increase in length during nymphal development. 


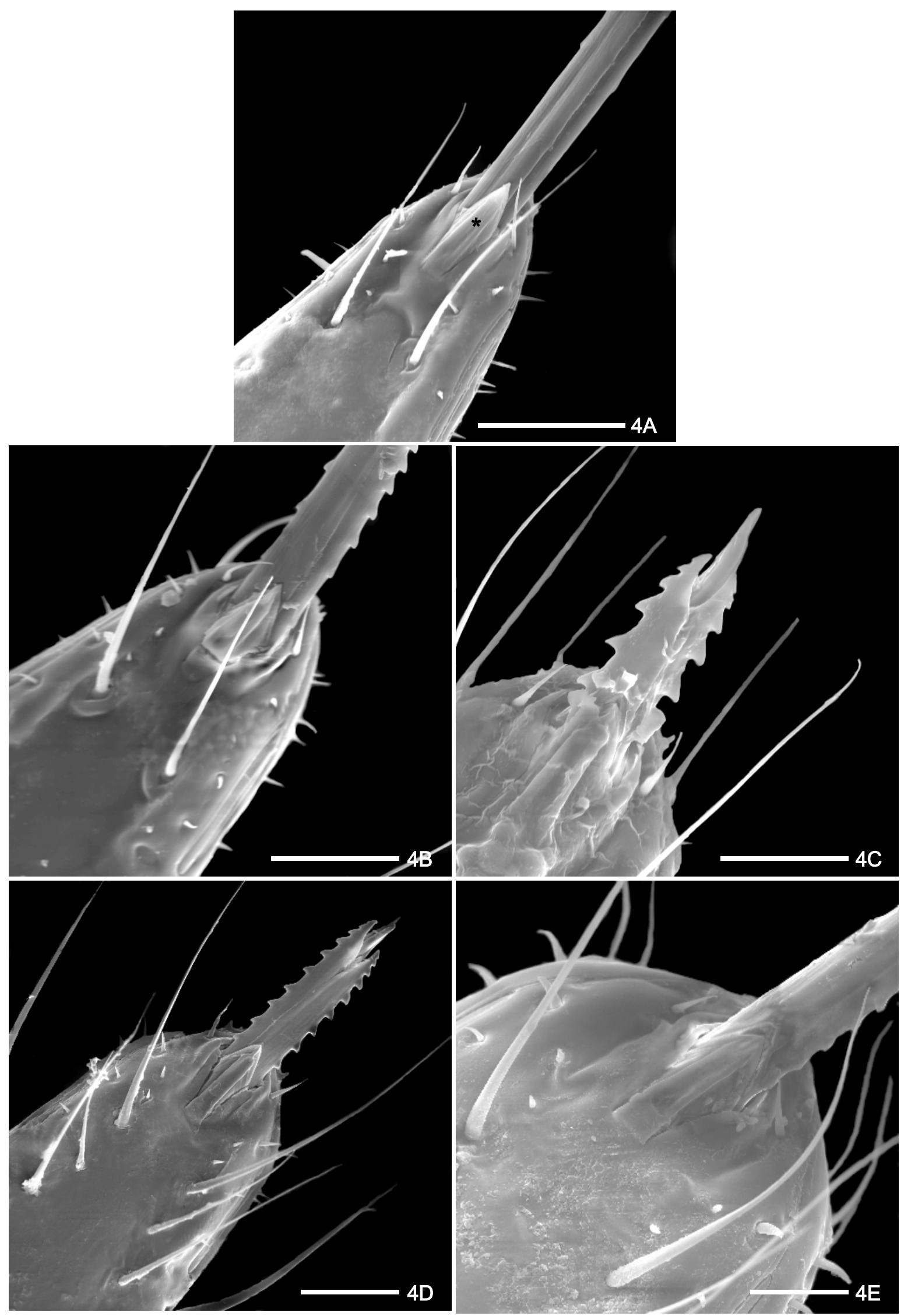

Fig. 4: Triatoma guazu Lent \& Wygodzinsky, 1979, ventral view: apex of the rostrum (asterisk = apical plate). A: 1st instar; B: 2nd instar; C: 3rd instar; D: 4th instar; E: 5th instar 


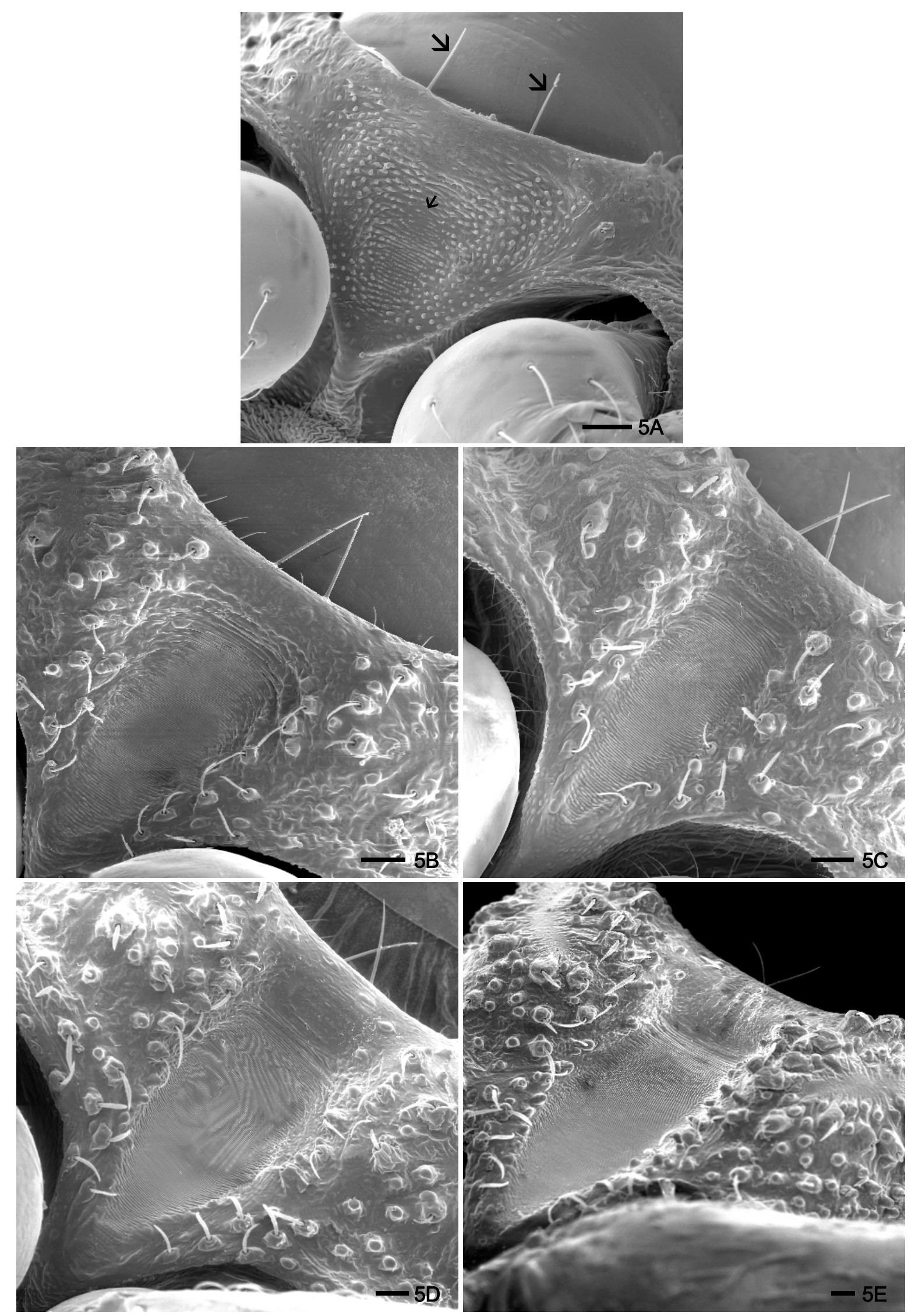

Fig. 5: Triatoma jurbergi Carcavallo, Galvão \& Lent, 1998, ventral view: prosternum and stridulatory sulcus. A: 1st instar (the small arrow shows rudimentary horizontal striae; the large arrows show two sensillae); B: 2nd instar; C: 3rd instar; D: 4th instar, 1; E: 5th instar 

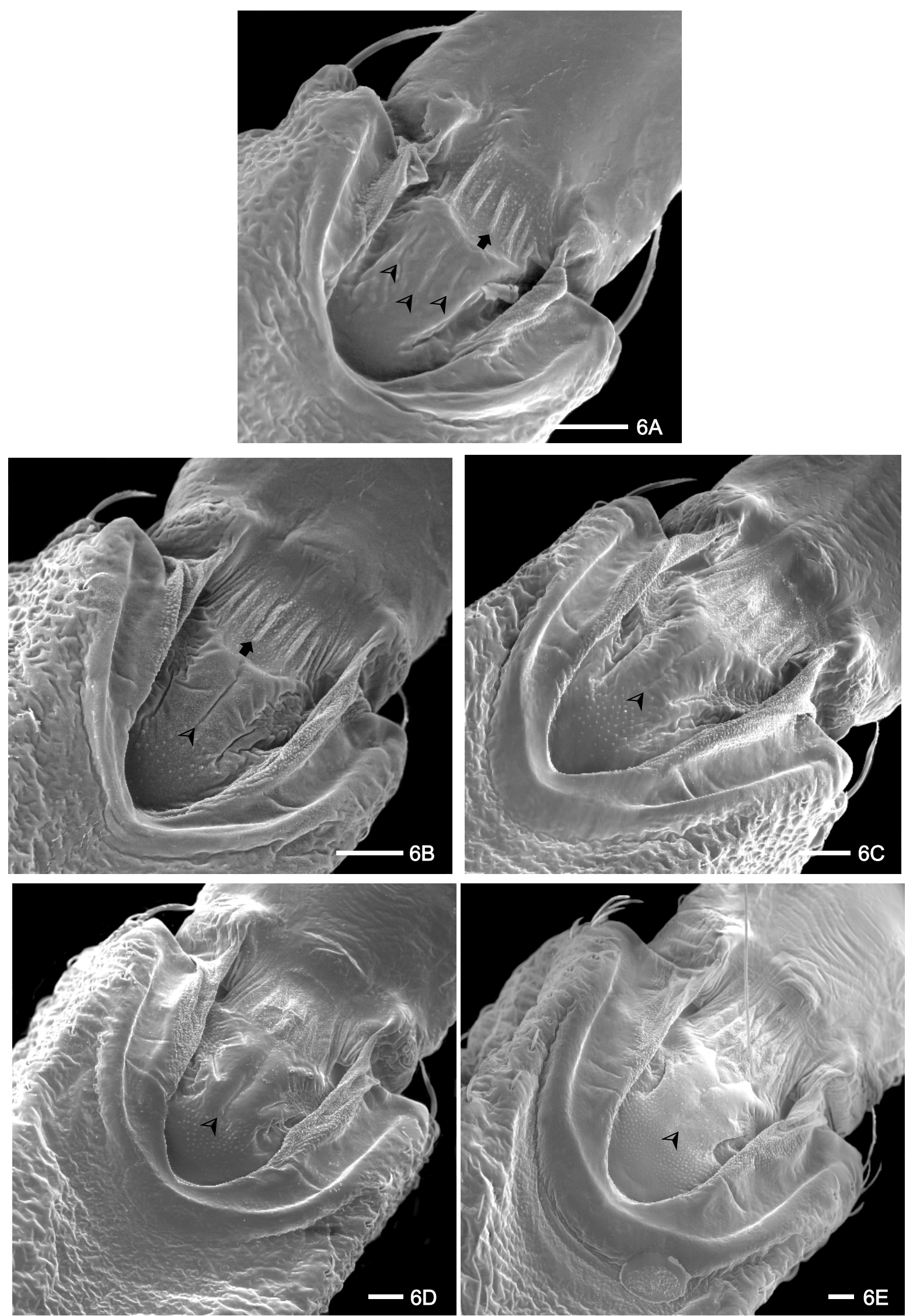

Fig. 6: Triatoma jurbergi Carcavallo, Galvão \& Lent, 1998, ventral view: buccula (the small arrows show sulcus and the arrow heads the rifts). A: 1st instar; B: 2nd instar; C: 3rd instar; D: 4th instar; E: 5th instar 


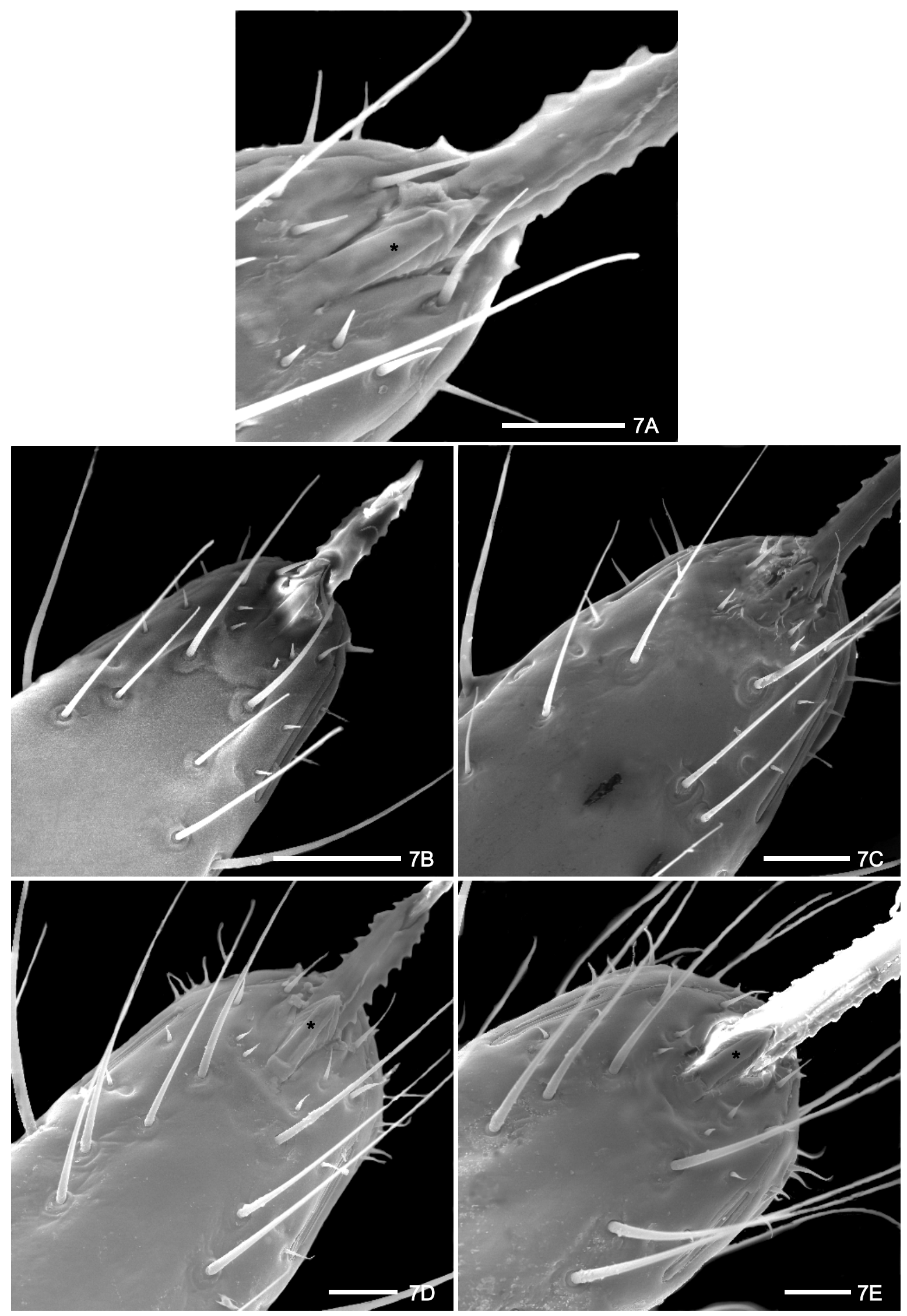

Fig. 7: Triatoma jurbergi Carcavallo, Galvão \& Lent, 1998, ventral view: apex of the rostrum (asterisk = apical plate). A: 1st instar; B: 2nd instar; C: 3rd instar; D: 4th instar; E: 5th instar 
the species was observed in the 1 st e 2 nd instars of $T$. guazu, which showed two long sensillae below of the apical plate along the longitudinal axis and two pairs of short sensillae, while in T. jurbergi these pairs of sensillae showed medium length in the two first instars.

The labial apical plate (Quadri 1951, Parsons 1966, Cobben 1978, Silva et al. 1999) was another parameter to differentiate species. We showed that $T$. guazu has this pair of structures limited by $1+1$ sensillae which present a large base, while, in T. jurbergi these structures are localized within a rectangular depression, have a lozenge form and the extern structure is digit form, limited by $3+3$ sensillae, which increase gradually in length. Two lateral rifts $1+1$ were observed close to the apex of the rostrum, that were modified during the nymphal development in both species, as described by Lent and Wygodzinsky (1979) in the genus Dipetalogaster Usinger, 1939 using optical microscopy. The data described here point out that these structures in T. guazu and T. jurbergi showed differences that may be used to distinguishing these species.

In conclusion, the ultrastructure of buccula, rostrum and the stridulatory sulcus presented in this study, associated to the morphologic characteristics of the antennae described previously by Silva et al. (2002), the exochorion of eggs and the morphometry of three characteristics of the eggs and of every nymphal stage (Silva et al. 2000, Jurberg et al. 2002) present different patterns of systematic value that allowed the taxonomic diagnosis of T. guazu and T. jurbergi nymph's. These data can be used as a tool to identify the two species both found in peridomiciliary habitats and one, T. jurbergi, found naturally infected with $T$. cruzi.

\section{ACKNOWLEDGMENTS}

To Bruno Ávila from Departamento de Ultra-estrutura e Biologia Celular, Instituto Oswaldo Cruz-Fiocruz, for the image processing. Two anonymous reviewers helped to improve the manuscript.

\section{REFERENCES}

Barth R 1953. Estudos anatômicos e histológicos sobre a subfamília Triatominae (Heteroptera, Reduviidae). III parte: Pesquisas sobre o mecanismo da picada dos Triatominae. Mem Inst Oswaldo Cruz 51: 11-68.

Carcavallo RU, Galíndez-Girón I, Catalá S, Jurberg J, Lent H, Galvão C, Barata JMS, Valderrama A 1998. Some anatomic structures studied with scanning electron microscopy (SEM). Algumas estruturas anatômicas estudadas com microscopia eletrônica de varredura (MEV). In RU Carcavallo, I Galíndez-Girón, J Jurberg, H Lent (eds) Atlas of Chagas' Disease Vectors in the Americas. Atlas dos Vetores da Doença de Chagas nas Américas, Fiocruz, Rio de Janeiro, Vol. I, p. 299-393.

Carcavallo RU, Galíndez-Gíron I, Jurberg J 1995. La región óculo-ocelar en género Psammolestes Bergroth, 1911 (Hemiptera, Reduviidae, Triatominae). Entomol Vect 2:113-116.

Carcavallo RU, Galíndez-Gíron I, Jurberg J, Martínez A 1994. La región óculo-ocelar en género Panstrongylus Berg,1879 (Hemiptera, Reduviidae, Triatominae). Entomol Vect 1: 113120.

Carcavallo RU, Jurberg J, Lent H, Noireau F, Galvão C 2000. Phylogeny of the Triatominae (Hemiptera: Reduviidae). Proposals for taxonomic arrangements. Entomol Vect 7: 1-99.

Carcavallo RU, Jurberg J, Rocha DS, Galvão C, Noireau F, Lent
$\mathrm{H}$ 2002. Triatoma vandae sp. $\mathrm{n}$. do complexo oliveirai encontrada no Estado de Mato Grosso, Brasil (Hemiptera: Reduviidae: Triatominae). Mem Inst Oswaldo Cruz 97: 649654.

Catalá S 1996. Sensila associated with the rostrum of eight species of Triatominae. J Morphol 228: 195-201.

Cobben RH 1978. Evolutionary trends in Heteroptera Part II. Mouthpart-structures and feeding strategies. Meded Landbouwhogeschool Wageningen 78: 5-407.

Costa J, Jurberg J Barth OM 1991. Estudos morfológicos de Cavernicola lenti Barrett \& Arias, 1985 (Hemiptera, Reduviidae, Triatominae). Mem Inst Oswaldo Cruz 86: 247-263.

Ferro ZPA, Barbosa HS, Jurberg J, Carcavallo RU 1997. The buccula and gula of Triatominae nymphs by scanning electron microscopy (Hemiptera: Reduviidae). Acta Microsc 6: 572-573.

Galindez-Girón I, Carcavallo RU, Jurberg J, Galvão C, Lent H, Barata JMS, Serra OP, Valderrama A 1998. External morphology and anatomy. Morfologia e anatomia externa. In RU Carcavallo, I Galíndez-Girón, J Jurberg, H Lent (eds), Atlas of Disease Vectors in the Americas. Atlas dos Vetores da Doença de Chagas nas Américas, Fiocruz, Rio de Janeiro, Vol. I, p. 53-83.

Galvão C, Patterson JS, Rocha DS, Jurberg J, Carcavallo C, Rajen K, Ambrose DP, Miles MA 2002. A new species of Triatominae from Tamil Nadu, India. Med Vet Entomol 16: 75-82.

Jurberg J 1996. A Taxonomia dos Triatomíneos Baseada nas Estruturas Fálicas (Hemiptera - Reduviidae), $\mathrm{PhD}$ thesis, Univiversidade Federal Rural do Rio de Janeiro, Itaguaí, $59 \mathrm{pp}$.

Jurberg J, Silva MBA, Galvão C, Rocha DS, Barbosa HS, Carcavallo RU 2002. Descrição dos ovos e dos cinco estádios ninfais de Triatoma jurbergi Carcavallo, Galvão \& Lent, 1998 vistos através de microscopia óptica e eletrônica de varredura (Hemiptera, Reduviidae). Mem Inst Oswaldo Cruz 97: 209-216.

Lent H, Wygodzisnky P 1979. Revision of the Triatominae (Hemiptera, Reduviidae) and their significance as vectors of Chagas' disease. Bull Amer Mus Natur Hist 163: 123520.

Parsons MC 1966. Labial skeleton and musculature of the Hydrocorisae (Heteroptera). Can J Zool 44: 1051-1084.

Pinto C 1931. Valor do rostrum e das antenas na caracterização dos triatomíneos. Boletim Biológico 19: 45-137.

Quadri MAH 1951. On the anatomy of the mouth-parts and mode of feeding in the aquatic bug (Cryptocerata). Proc Zool Soc Beng 4: 117-135.

Silva MBA, Barbosa HS, Carcavallo RU, Galvão C, Jurberg J 1999. Placas apicais do lábio das ninfas de $1^{\circ}$ estádio de Triatoma guazu Lent \& Wygodzinsky, 1979 e Triatoma jurbergi Carcavallo, Galvão \& Lent, 1998 (Hemiptera, Reduviidae), vetores da doença de chagas. Entomol Vect 6: 663668.

Silva MBA, Barbosa HS, Jurberg J, Galvão C, Carcavallo RU 2002. Comparative ultrastructural analysis of the antennae of Triatoma guazu and Triatoma jurbergi during the nymphal stage development (Hemiptera, Reduviidae). JMed Entomol 39: 705-715.

Silva MBA, Jurberg J, Galvão C, Barbosa HS, Carcavallo RU 1998. Some insufficiently know cuticular structures of the first instar of Triatoma guazu Lent \& Wygodzinsky, 1979. Mem Inst Oswaldo Cruz 93: 345.

Silva MBA, Jurberg J, Galvão C, Carcavallo RU 2000. Estudo morfológico e morfométrico de ovos e ninfas de Triatoma guazu Lent \& Wygodzzinsky, 1979 (Hemiptera, Reduviidae, Triatominae) vistos por microscopia óptica e eletrônica de varredura. Entomol Vect 7: 311-334. 